\title{
LA DIMENSIÓN OBJETIVA DE LOS DERECHOS FUNDAMENTALES EN MÉXICO
}

\author{
The Objective Dimension of \\ Fundamental Rights in Mexico
}

\section{A DIMENSÃO OBJETIVA DOS DIREITOS FUNDAMENTAIS NO MÉXICO}

JOSÉ JUAN ANZURES GURRÍA*

* $\quad$ orcid.org/0000-0002-8257-8687. Tecnológico de Monterrey. México. anzuresgurria@itesm.mx

RECIBIDO: 21 DE FEBRERO DE 2016. ENVÍO A PARES: 18 DE MAYO DE 2016 APROBADO POR PARES: 13 DE DICIEMBRE DE 2016. ACEPTADO: 16 DE ENERO DE 2017

DOI: $10.5294 / D I K A .2017 .26 .1 .4$

PARA CITAR ESTE ARTÍCULO / TO REFERENCE THIS ARTICLE / PARA CITAR ESTE ARTIGO 


\section{RESUMEN}

El objeto del presente trabajo pretende abordar la dimensión objetiva de los derechos fundamentales en nuestro país. Concebir a los derechos fundamentales en su dimensión objetiva trae consigo tres consecuencias principales, el efecto irradiación de los derechos, los mandatos de acción al Estado y la eficacia horizontal de los derechos. El aspecto que parece más problemático es este último, y no tanto desde su construcción teoría sino sobre todo desde su solución adjetiva, toda vez que el Juicio de amparo parece seguir siendo improcedente contra las violaciones a los derechos fundamentales que procedan de tercero. Como los mayores desarrollos teóricos y prácticos del tema provienen eminentemente de Alemania, se recurre de manera reiterada a la doctrina de este país, que además ha influenciado a casi todos los países europeos, por lo que recurrimos también a la doctrina y a la jurisprudencia de España. Al tiempo que analizamos los aportes de estos países, estudiamos nuestro texto constitucional y nuestra jurisprudencia constitucional a efectos de identificar la forma en que estamos adoptando estas teorías.

\section{PALABRAS ClaVe}

Derechos fundamentales; dimensión objetiva; eficacia; efecto de irradiación; eficacia horizontal. 


\section{ABSTRACT}

The purpose of this paper is to address the objective dimension of fundamental rights in Mexico. Perceiving fundamental rights in their objective facet has three main consequences: the irradiation effect of rights, the mandates regarding action by the State, and the horizontal effectiveness of rights. This last aspect appears to be the most problematic, not so much because of its theoretical construction, but primarily with respect to its adjective solution, since amparo proceedings against final judicial decisions for which there is no legal remedy or recourse still seem to be inadmissible against violations of fundamental rights that originate with third parties. Since the major theoretical and practical developments on this subject come largely from Germany, the doctrine of that country is resorted to repeatedly. It also has influenced nearly all the European countries, which is why the authors also refer to the doctrine and jurisprudence of Spain. In analyzing the contributions of these countries, the authors examine the text of their own country's constitution and its constitutional jurisprudence in an effort to identify how these theories are being adopted in Mexico.

\section{KEYWORDS}

Fundamental rights; objective dimension; effectiveness; irradiation effect; horizontal effectiveness. 


\section{RESUMO}

Este trabalho pretende abordar a dimensão objetiva dos direitos fundamentais no México. Conceber esses direitos em sua dimensão objetiva traz consigo três consequências principais: o efeito irradiação dos direitos, os mandatos de ação ao Estado e a eficácia horizontal dos direitos. $\mathrm{O}$ aspecto que parece mais problemático é este último; não tanto por sua construção teórica, mas principalmente por sua solução adjetiva, já que o juizo de amparo parece continuar sendo improcedente contra as violações dos direitos fundamentais realizadas por terceiro. Como o maior desenvolvimento teórico e prático do tema provém eminentemente da Alemanha, recorre-se, de maneira reiterada, à doutrina desse país, que, além disso, tem influenciado quase todos os países europeus; por essa razão, também recorremos à doutrina e à jurisprudência da Espanha. Ao mesmo tempo que analisamos as contribuições desses países, estudamos nosso texto constitucional e nossa jurisprudência constitucional a fim de identificar a forma como estamos adotando essas teorias.

\section{PALAVRAS-CHAVE}

Dimensão objetiva; direitos fundamentais; efeito de irradiação; eficácia; eficácia horizontal. 
Sumario: Introducción; 1. La dimensión objetiva de los derechos fundamentales; 1.1. Mandatos de acción al estado; 1.2. El efecto irradicación; 1.3. La eficacia horizontal; 1.4. La asunción judicial; 2. Conclusiones; Bibliografía.

\section{INTRODUCCIÓN}

La Carta Magna del año 1215, suscrita por el monarca Juan sin Tierra, es recordada todavía como el primer documento que impuso ciertos límites al poder de un rey. Si bien es cierto que los derechos reconocidos en ese documento fueron prerrogativas tributarias, y para nada derechos de las personas como los entendemos hoy en día, es innegable que desde su más antigua concepción, y a lo largo de su evolución, los derechos fundamentales han sido concebidos como límites al poder del Estado.

En las declaraciones de derechos de finales del siglo XVIII, y su posterior incorporación a los textos constitucionales, los derechos, como las constituciones mismas, fueron concebidos también como derechos de las personas oponibles al poder del monarca o del recién constituido Estado. A lo largo del periodo decimonónico, las distintas teorías sobre los derechos fundamentales siguieron considerando que estos eran límites al poder del Estado, y que este, en un ejercicio de autolimitación, los concedía a sus habitantes.

No fue sino después de la Segunda Guerra Mundial, cuando la Ley Fundamental de Bonn recogió en su texto el concepto de derechos fundamentales, que estos fueron concebidos e interpretados con posterioridad por el Tribunal de Karlsruhe, no solo como derechos subjetivos que cada persona opone frente al poder del Estado, sino como un conjunto de principios y valores que constituyen la base sobre la cual se construye todo Estado constitucional y democrático de derecho.

A la concepción originaria de los derechos como límites al poder se le ha denominado dimensión subjetiva, mientras que aquella que los considera principios y valores se ha llamado dimensión objetiva. Esta última no viene a desplazar sino a complementar la concepción originaria de los derechos fundamentales pero, además, vino a revolucionar el derecho constitucional y con él, al mismo Estado, y es que el reconocimiento de los derechos fundamentales como principios y valores del ordenamiento jurídico implica su reconocimiento como previos y superiores a la organización politica, o si se quiere, como conceptos aceptados por toda la comunidad y por ello imprescindibles para la construcción del Estado.

Esta "revolución" conceptual y fáctica de los derechos fundamentales y, en consecuencia, de la organización estatal, ha surtido sus efectos no solo en Alemania o Europa, sino en todo el mundo occidental, incluido naturalmente México, aunque ciertamente después de muchos años. Mientras que en Europa se empezaba a hablar de la dimensión objetiva de los derechos fundamentales, tanto en el ámbito jurisprudencial como académico, desde los años cincuenta, en nuestro país el tema parece todavia novedoso, lejano o incluso ajeno a nuestra realidad jurídica. 
La reforma constitucional de 2011 en materia de derechos humanos, si bien constituyó una cambio de paradigma y una "puesta al día" en estos derechos, no fue una reforma que incluyera la doctrina constitucional más avanzada sino más bien los conceptos del derecho internacional de los derechos humanos (DIDH). La misma reforma se denominó en "derechos humanos" y no en "derechos fundamentales"; y es por eso quizá que, a pesar del gran calado de la reforma, en ninguna parte del texto constitucional se observa de manera expresa el reconocimiento de la dimensión objetiva de los derechos fundamentales, lo que no significa que no se reconozca.

Ante esta imprecisión por parte de nuestro texto constitucional, incluso después de la mencionada reforma de 2011, el presente trabajo pretende abordar y demostrar el reconocimiento de la dimensión objetiva de los derechos fundamentales en nuestro país. Para esto se analiza el concepto y el reconocimiento que se ha hecho por la doctrina y los tribunales de Alemania y España. En México se estudia el texto constitucional y se analizan las más recientes resoluciones de la Suprema Corte de Justicia de la Nación. Habiendo identificado el reconocimiento de la dimensión objetiva de los derechos fundamentales en nuestro país se analizan las tres principales consecuencias de su reconocimiento, que son: el efecto irradiación de los derechos, los mandatos de acción al Estado y la eficacia horizontal de los derechos.

Del estudio de cada uno de estos aspectos, el que ha provocado mayor discrepancia y discusión es el denominado "eficacia horizontal de los derechos", pues viene a poner en tela de juicio la clásica concepción de los derechos como límites al poder del Estado para concebirlos como límites al poder de los particulares, y el meollo aquí radica, no tanto en su construcción teórica, sino en su solución adjetiva, razón por la cual se dedica la última parte del trabajo a esta cuestión.

\section{LA DIMENSIÓN OBJETIVA DE LOS DERECHOS FUNDAMENTALES}

Si bien es cierto que los derechos fundamentales tienen su acta de nacimiento en 1776 con la Declaración de Virginia ${ }^{1}$ como derechos propios del Estado liberal y positivizados en una Constitución, el término, formalmente hablando, no existió propiamente durante el periodo decimonónico, sino hasta su incorporación en la Ley Fundamental de Bonn de 1948, diferenciándose incluso de los derechos humanos (Menschenrecht). Se trata pues de una categoría dogmática propia del constitucionalismo, en general, y del constitucionalismo de la segunda posguerra, en concreto. ${ }^{2}$

1 Según Cruz Villalón, el acta de nacimiento de los Derechos fundamentales comienza en 1776, ni antes ni después. P. Cruz villalón, "Formación y evolución de los derechos fundamentales", Revista española de Derecho Constitucional, Año 925 (1989), p. 41. 
Cuando se reconocieron los derechos fundamentales en las declaraciones de derechos de finales del siglo XVIII, lo hicieron, como era propio de la época, como derechos subjetivos, esto es, como derechos de cada persona individualmente considerada y que oponian frente al poder del Estado; se considera que los derechos fundamentales son normas de competencia negativas que delimitan esferas de autonomía del individuo en las cuales el poder estatal no puede intervenir.

Esta subjetividad de los derechos se observa desde entonces y durante el siglo XIX en independientemente de las categorias conceptuales que tratan de definir los derechos inherentes a las personas; así, en la doctrina alemana, nace del intelecto de G. Jellinek el concepto de derechos públicos subjetivos, entendidos como "la potestad que tiene el hombre, reconocida y protegida por el ordenamiento jurídico en cuanto se dirige a un bien o a un interés"; si bien es cierto que en esta concepción, estos derechos solo pueden ser exigibles por cada persona en tanto es considerada miembro del Estado. En la doctrina francesa del siglo XIX se habló de las libertades públicas, entendidas de igual forma como aquellos derechos que cada individuo puede oponer frente al poder del Estado, en tanto la persona forma parte del mismo.

No fue sino hasta la introducción formal del término derechos fundamentales (Grundrechte) en el constitucionalismo de la Segunda posguerra, que estos derechos son entendidos no solo en su dimensión individual, sino también en su dimensión objetiva. Mientras los anteriores conceptos contenían solo una dimensión individual, el concepto de derechos fundamentales comprende además una objetiva. Esta dimensión o función objetiva (Die objektiv-rechtliche Funktion der Grundrechte) ${ }^{3}$ se refiere a que los derechos fundamentales ya no son solo derechos que cada persona tiene y opone frente al poder del Estado, sino que, además, se constituyen en principios y valores del ordenamiento jurídico del Estado constitucional y democrático de derecho. ${ }^{4}$

El contenido axiológico de los derechos fundamentales había sido puesto ya de manifiesto por R. Smend en la redacción de la Constitución de Weimar de 1919 al considerar que dicha Carta Magna debía reconocer a los derechos fundamentales no solo como derechos de cada persona frente al poder del Estado, sino, además, como un orden material de valores que integraba e inspiraba el desarrollo de todo el orden jurídico y político estatal, un conjunto de principios que reflejaba las bases sobre las cuales la comunidad política funcionaba y había decidido organizarse y

3 B. Pieroth y B. Schlink, Grundrechte Staatsrecht II, Heidelberg, Müller Verlang, 1998, pp. 20 y ss.

4 En palabras de BöcKENFöRdE, la dimensión objetiva de los derechos fundamentales no es un complemento sino una cualidad de los derechos. E. W. BöcKENFöRdE, "Sobre la situación de la dogmática de los derechos fundamentales tras 40 años de la ley fundamental”, en E. W. BöcKEnFörde, Escritos sobre derechos fundamentales, Baden-Baden, Nomos Verlagsgesellschaft, 1993, p. 109. Para R. AleXY se trata del "instrumento más importante para permitir que estos derechos adquieran un nuevo contenido". R. AlEXY, Grundrechte als subjektive Rechte und als objektive Normen, en Recht, Vernunft, Diskurs, Frankfurt/M, Suhrkamp, 1995, p. 262. 
constituirse como Estado; ${ }^{5}$ o sea que los derechos fundamentales recogen (o son) conceptos metajurídicos, previos y superiores al Estado. ${ }^{6}$

Ahora, en tanto los derechos fundamentales son concebidos como principios y valores del ordenamiento jurídico, resulta preciso determinar la diferencia entre estos conceptos. ${ }^{7}$ Los principios pertenecen al mundo del deber ser, por lo que son ideales por alcanzar; los valores son cuestiones buenas en sí mismas, que valen independientemente del grado de apreciación que les demos; ${ }^{8}$ en consecuencia, decir que los derechos fundamentales son valores y principios significa que son cosas buenas en sí mismas e ideales que la comunidad debe alcanzar; y por eso mismo se constituyen en directrices constitucionales y reglas de actuación de los poderes públicos. ${ }^{9}$

Según el sistema de valores de G. Dürig, la dignidad humana es el valor supremo del ordenamiento jurídico. Así, de la dignidad humana se desprenden todos los derechos fundamentales entendidos como valores, principalmente la libertad y la igualdad, y de ellos todos los demás, por lo que la dignidad funciona como criterio interpretativo de todos los derechos, donde cualquier violación de estos es una violación a la dignidad humana y cualquier violación a esta es una violación de los derechos fundamentales.

La dimensión objetiva de los derechos fundamentales con la dignidad humana en la cúspide de todo el ordenamiento jurídico ha sido acogida por casi todo el constitucionalismo de la Segunda posguerra, tanto en Europa como en América latina. En este sentido, Alemania reconoció en el artículo 1.2. de la Ley Fundamental de Bonn que "el pueblo alemán declara [...], su adhesión a los inalienables e inviolables derechos humanos como fundamento (grund) de toda comunidad humana, de la paz y de la justicia en el mundo". Por su parte, el Tribunal Constitucional de este país reconoció la dimensión objetiva de los derechos fundamentales en la sentencia Lüth, ${ }^{10}$ en la que consideró que las normas en que se

5 Cfr. R. Smend, Constitución y derecho constitucional, Madrid, Centro de Estudios Políticos y Constitucionales de Madrid, 1985, p. 232.

6 Cfr. P. Marshall Barberán, "Los derechos fundamentales como valores", Revista Telemática de Filosofia del Derecho 10 (2006/2007), pp. 207-228.

$7 \quad$ "Lo que en el modelo de los valores es lo mejor prima facie, en el mundo de los principios es debido prima facie; y lo que en el modelo de los valores es lo mejor en definitiva, en el modelo de los principios es debido en definitiva”. R. ALEXY, Teoría de los derechos fundamentales, op. cit., p. 125.

8 Cfr. Idem, p. 120 y ss. Julián MARíAs señala que cuando uno prefiere una cosa sobre otra, es porque esa cosa tiene valor. "Los valores son algo que tienen las cosas, que ejerce sobre nosotros una extraña presión; no se limitan a estar ahí, a ser aprehendidos, sino que nos obligan a estimarlos, a valorarlos. Podré ver una cosa buena y no buscarla; pero lo que no puedo hacer es no estimarla. Verla como buena es ya estimarla [...] Valor, pues, es aquello que tienen las cosas que nos obliga a estimarlas. J. MARIAS, "La teoría de los valores", en Historia de la Filosofia, Revista de Occidente 20 (1967), pp. 406-412.

9 H. P. Schneinder, "Peculiaridad y función de los derechos fundamentales en el Estado constitucional democrático”, en Revista de Estudios Políticos 7 (1979), Madrid, Centro de Estudios Constitu-

$60 \quad$ cionales, p. 23, nota 4 . da por un productor simpatizante, en su tiempo, con el régimen nacional socialista. El productor reaccionó y consiguió del juez una orden para que el periodista se abstuviese de seguir llamando 
plasman los derechos fundamentales contienen no solo derechos subjetivos reaccionales del individuo frente al Estado, sino que a un mismo tiempo incorporan un orden axiológico objetivo que, en su condición de decisiones constitucionales básicas, vale para todos los ámbitos del derecho, proporcionando directrices e impulsos para la legislación, la administración y la jurisprudencia.

En España, la dimensión objetiva de los derechos fundamentales se reconoció de manera expresa en el artículo 1 de la Constitución de 1978 al señalar que: "España se constituye en un Estado social y democrático de Derecho, que propugna como valores superiores de su ordenamiento jurídico la libertad, la justicia, la igualdad y el pluralismo político". También su artículo 10.1 señala que "la dignidad de la persona, los derechos inviolables que les son inherentes, el libre desarrollo de la personalidad, el respeto a la Ley y a los derechos de los demás son fundamento del orden político y de la paz social".

Por su parte, la jurisprudencia española ha reconocido en varias ocasiones esta dimensión objetiva de los derechos fundamentales. Así lo hizo el Tribunal Constitucional de este país al señalar en su sentencia 25/1981, de 14 de julio (F.J. 5º.) que:

...los derechos fundamentales son derechos subjetivos, [...]. Pero al propio tiempo, son elementos esenciales de un ordenamiento creativo de la comunidad nacional, en cuanto esta se configura como marco de una convivencia humana justa y pacífica, plasmada históricamente en el Estado de derecho y, más tarde, en el Estado social de derecho o Estado social y democrático de derecho.

De igual forma, la sentencia 53/1985, de 11 de abril (F.J. 4º.) señaló que:

...los derechos fundamentales son los componentes estructurales básicos, tanto del conjunto del orden jurídico objetivo como de cada una de las ramas que lo integran, en razón de que son expresión jurídica de un sistema de valores que, por decisión del constituyente, ha de informar el conjunto de la organización jurídica y política; son, en fin, como dice el artículo 10 de la Constitución española, el "fundamento del orden jurídico y la paz social". ${ }^{11}$

En México, la dimensión objetiva de los derechos fundamentales no se reconoce expresamente en nuestro texto constitucional, en ningún lugar se señala que el Estado mexicano se fundamenta en la dignidad de la persona, ni se mencionan los derechos fundamentales como principios y valores de su ordenamiento jurídico, como lo hacen otras constituciones de otros países. ${ }^{12}$ Pero si hacemos una

al boicot. Ante esta decisión, el periodista apeló al Tribunal Constitucional, que recordó que el derecho de libre expresión no se aplica directamente a las relaciones entre particulares. No obstante, consideró que tribunal inferior había obrado incorrectamente, porque no consideró el efecto que los derechos fundamentales ejercían sobre las normas de derecho civil. El tribunal Constitucional falló, por tanto, protegiendo al periodista en sus actuaciones.

11 Véase también, entre otras, la STC 163/1986 de 17 de diciembre.

12 Así el artículo 1 de la Constitución de Colombia señala que "Colombia es un Estado social de derecho, organizado en forma de República unitaria, descentralizada, con autonomía de sus en- 
interpretación armónica de los artículos $1^{\circ}, 2^{\circ}, 3^{\circ}$ y 25 de nuestra Constitución, donde se recoge el término "dignidad", parece que esta sí es el fundamento de todo nuestro ordenamiento jurídico. Esto es así al prohibir toda conducta, sin importar que provenga de un particular o de una autoridad estatal, que atente contra la dignidad; al reconocer en el artículo 2 que somos un Estado plural, compuesto por comunidades indigenas, pero que esta pluralidad no puede atentar contra la dignidad de la mujer, precisamente porque la dignidad es el fundamento de esa pluralidad; y, por último, al señalar que tanto la educación del Estado como la rectoría del desarrollo nacional deben estar orientadas al aprecio, respeto y pleno ejercicio de la dignidad de la persona.

Aunado a lo anterior, ya nuestra SCJN reconoció en el año 2009, que la dignidad humana es condición y base del orden jurídico mexicano y de los demás derechos fundamentales. ${ }^{13}$ Esta resolución, no obstante, no aclara si se reconoce a la dignidad como el valor supremo de todo el ordenamiento jurídico según la teoría de los valores de G. Dürig, o si se le reconoce como un derecho fundamental más; y es que el mismo texto señala que la dignidad humana es un valor supremo y más adelante que se trata de "un derecho absolutamente fundamental". La distinción no es baladí porque si se considera a la dignidad como valor supremo se entenderá que es un criterio interpretativo de todos los derechos fundamentales reconocidos en esta; si se entiende como un derecho fundamental nacen para el Estado obligaciones determinadas a fin de garantizar su pleno ejercicio, además de que tendría que delimitarse su contenido constitucionalmente protegido. Esta confusión parece aclararse un poco cuando en la Tesis jurisprudencial de rubro "Dignidad humana. Su naturaleza y concepto", ${ }^{14}$ se señala que "la dignidad humana es un valor supremo establecido en el artículo 1 de la Constitución Política de los Estados Unidos Mexicanos”, y así aunque nuestra Constitución no lo señale expresamente, debemos entender que esta se constituye en el valor supremo de nuestro ordenamiento jurídico.

Además, la Primera Sala de la SCJN ha reconocido la doble dimensión de los derechos fundamentales al señalar de manera expresa que estos tienen una dimensión

tidades territoriales, democrática, participativa y pluralista, fundada en el respeto de la dignidad humana, en el trabajo y la solidaridad de las personas que la integran y en la prevalencia del interés general”. En su artículo 2 señala que son fines esenciales del Estado: servir a la comunidad, promover la prosperidad general y garantizar la efectividad de los principios, derechos y deberes consagrados en la Constitución. El artículo 5 de la Constitución de Nicaragua señala que son principios de la nación nicaragüense: la libertad; la justicia; el respeto a la dignidad de la persona humana; el pluralismo político, social y étnico; el reconocimiento a las distintas formas de propiedad; la libre cooperación internacional; y el respeto a la libre autodeterminación de los pueblos. El artículo 5 de la Constitución de Chile señala que "es deber de los órganos del Estado respetar y promover tales derechos (derechos esenciales que emanan de la naturaleza humana) garantizados por esta Constitución, así como por los tratados internacionales ratificados por Chile y que se encuentren vigentes".

13 Dignidad humana. El orden jurídico mexicano la reconoce como condición y base de los demás derechos fundamentales. [TA]; 9a. Época; Pleno; SJF y su Gaceta; Tomo XXX, diciembre de 2009; p. 8.

14 Dignidad humana. Su naturaleza y concepto. [J]; 10a. Época; TCC; SJF y su Gaceta; Libro I, octubre de 2011, Tomo 3; p. 1529. 
subjetiva y otra objetiva, aunque respecto de esta última no señala claramente que los derechos fundamentales sean principios y valores del ordenamiento jurídico, sino simplemente una "normativa más abstracta y general" en virtud de la cual los derechos "unifican, identifican e integran, en un sistema jurídico determinado, a las restantes normas que cumplen funciones más especificas”. ${ }^{15}$

Ciertamente, ya en el 2004, el Cuarto Tribunal Colegiado en Materia Administrativa del Primer Circuito había reconocido que la Constitución contiene principios y valores, y que había de acudirse a ellos al interpretar las leyes infraconstitucionales, incluso esta tesis aislada define los principios como "postulados que persiguen la realización de algo como expresión directa de los valores incorporados al sistema jurídico", pero no menciona expresamente que los derechos fundamentales sean principios y valores del ordenamiento. ${ }^{16}$

El reconocimiento de los derechos fundamentales como principios se hace en una Tesis aislada del Segundo Tribunal Colegiado en Materia Administrativa del Cuarto Circuito al señalar que se trata de:

...principios (que) representan criterios de optimización interpretativa de los derechos fundamentales, porque conducen a su realización y observancia plena e inmejorable a favor del individuo (y que orientan) el proceder de toda autoridad en el cumplimiento del mandato de promover, respetar, proteger y garantizar los derechos humanos reconocidos en la Constitución y los tratados internacionales de la materia. ${ }^{17}$

Aunado a lo anterior, la Sala Primera de la SCJN reconoció que la igualdad se configura como uno de los valores superiores del orden jurídico, "lo que significa que ha de servir de criterio básico para la producción normativa y su posterior interpretación y aplicación”, y es importante destacar que más adelante la tesis hace la distinción de la igualdad como principio y valor, en tanto aspecto valioso en sí mismo y, por tanto, como un fin por ser alcanzado. ${ }^{18}$

15 Derechos fundamentales. Su dimensión subjetiva y objetiva. [TA]; 10a. Época; 1a. Sala; SJF y su Gaceta; Libro XVI, enero de 2013, Tomo 1; p. 627. En los mismos términos la reciente Tesis jurisprudencial $1^{\mathrm{a}} / \mathrm{J}$. 43/2016 $\left(10^{\mathrm{a}}\right)$. Ya en una jurisprudencia de rubro: Derechos fundamentales. $\mathrm{Su}$ vigencia en las relaciones entre particulares, del año 2012, nuestra SCJN señaló también que los derechos fundamentales "se traducen en elementos objetivos que informan o permean todo el ordenamiento jurídico” [J]; 10a. Época; 1a. Sala; SJF y su Gaceta; Libro XIII, octubre de 2012, Tomo 2; p. 798.

16 Principios y valores consagrados en la constitución. Debe atenderse a ellos cuando las leyes son insuficientes para resolver una controversia. [TA]; 9a. Época; TCC; SJF y su Gaceta; Tomo XX, septiembre de 2004; p. 1836.

17 Principios de universalidad, interdependencia, indivisibilidad y progresividad establecidos en la Constitución federal. Representan criterios de optimización interpretativa de los derechos fundamentales. [TA]; 10a. Época; TCC; SJF y su Gaceta; Libro XXI, junio de 2013, Tomo 2; p. 1289.

18 La tesis señala: "el valor superior que persigue este principio consiste en evitar que existan normas que, llamadas a proyectarse sobre situaciones de igualdad de hecho, produzcan como efecto de su aplicación la ruptura de esa igualdad al generar un trato discriminatorio entre situaciones análogas, o bien, propicien efectos semejantes sobre personas que se encuentran en situaciones dispares, lo que se traduce en desigualdad jurídica”. Igualdad. Limites a este principio. [J]; 9a. Época; 1a. Sala; SJF y su Gaceta; Tomo XX, octubre de 2004; p. 99. 
A partir de lo anterior podemos afirmar que, aunque de manera aún no consolidada, en nuestro país se reconoce la dimensión objetiva de los derechos fundamentales; la cuestión redunda en que esta dimensión trae consigo tres consecuencias que vienen a cambiar por completo el tradicional entendimiento que se tenía de dichos derechos. Estas consecuencias son: 1) los mandatos de acción o conductas positivas por parte del Estado; 2) el efecto irradiación de los derechos fundamentales; y 3) su eficacia en las relaciones particulares.

\subsection{Mandatos de acción al Estado}

Concebir a los derechos fundamentales como principios y valores del ordenamiento jurídico significa que dejan de ser solo limites al poder del Estado para convertirse en mandatos que deben cumplirse por parte de este. ${ }^{19}$ En consecuencia, el Estado se encuentra vinculado a los derechos fundamental de una doble manera, por un lado, en su sentido tradicional, absteniéndose de lesionar la esfera jurídica de las personas y, por el otro, en cuanto a su dimensión objetiva, procurando que el disfrute de los derechos sea real y efectivo en todos los sectores del ordenamiento jurídico. ${ }^{20}$

Los mandatos de acción que nacen de la dimensión objetiva de los derechos fundamentales han sido aceptados en varias ocasiones por la doctrina y la jurisprudencia constitucional de distintos países. Así, en la sentencia 129/1989 de 17 de julio, el Tribunal Constitucional de España reconoció que: "el significado que los derechos adquieren dentro del orden constitucional impone a los poderes públicos el deber de garantizar su efectiva vigencia y, especialmente, obliga al legislador a proteger los valores positivados y formalizados en el ordenamiento a través de los derechos fundamentales”. También, en su Auto 382/1996, de 18 de diciembre, el máximo Tribunal de España indicó que:

19 BöcKENFöRDE señala: "Los derechos fundamentales como normas de principio o decisiones axiológicas denotan un contenido normativo determinado que exige ser realizado; no son derechos que persigan la abstención, sino que pretenden la actuación y la protección de estos contenidos”. Más adelante, afirma este mismo autor que: "El deber de protección del Estado es general. No solo prohíbe - evidentemente- intervenciones estatales directas en la vida que se está gestando, sino que obliga también al Estado a situarse ante esta vida en términos de protección y promoción, es decir, a protegerla frente a ataques antijurídicos por parte de otros”. E. W. BöcKENFÖRDE, Sobre la situación de la dogmática, op. cit., pp. 114 y 115.

20 L. M. Dízz-Picazo, Sistema de derechos fundamentales, op. cit., p. 63; M. Venegas Grau, Derechos fundamentales y derecho privado. Los derechos fundamentales en las relaciones entre particulares y el principio de autonomía privada, Madrid, Marcial Pons, 2004, p. 173. En este sentido, la STC 18/1984 en su FJ $3^{\circ}$, señala que "La configuración del Estado como social de derecho viene así a culminar una evolución en la que la consecución de los fines de interés general no es absorbida por el Estado, sino que se armoniza en una acción mutua Estado-sociedad, que difumina la dicotomía derecho público-privado y agudiza (tanto) la dificultad de calificar determinados entes, cuando no existe calificación legal, como (la) de valorar la incidencia de una nueva regulación sobre su naturaleza jurídica”. Más adelante, en su FJ 6º, esta misma sentencia señala que: "la sujeción de los poderes públicos a la Constitución (art. 9.1) "se traduce en un deber positivo de dar efectividad a tales derechos en cuanto a su vigencia en la vida social'. La petición del principio es evidente: habría un deber de los poderes públicos de 'dar efectividad' a los derechos fundamentales 'en cuanto a su vigencia en la vida social' que deriva del artículo 9.1 de la Constitución”. 
...como consecuencia de este doble carácter de los derechos fundamentales, pende sobre los poderes públicos una obligación también dual, [...] en su vertiente jurídico-objetiva, reclaman genéricamente de ellos que, en el ámbito de sus respectivas funciones, coadyuven a fin de que la implantación y disfrute de los derechos fundamentales sean reales y efectivos, sea cual fuere el sector del ordenamiento en el que los mismos resulten concernidos.

En México, a pesar de que la reforma de 10 de junio de 2011 no incorporó expresamente en el texto constitucional la dimensión objetiva de los derechos fundamentales, sí contempló por contra en el párrafo tercero del artículo $1^{\circ}$ de la Constitución Politica de los Estados Unidos Mexicanos (CPEUM) ${ }^{21}$ los mandatos de acción o las conductas positivas hacia el Estado a efectos de hacer realmente efectivos estos derechos.

Los mandatos de acción que este artículo comprende vinculan a todas las autoridades en todos los niveles de Gobierno. En el caso del legislador, este deberá regular y concretar los derechos para hacerlos verdaderamente efectivos. Así lo reconoce la tesis aislada de rubro "Derechos fundamentales. Su relación con el poder de policía”, al señalar que:

...los derechos fundamentales, en abstracto, constituyen mandatos que no están condicionados en cuanto a su ejercicio, antes bien deben ser optimizados; sin embargo, cuando cobran vigencia y se aplican, existe una serie de normas que establecen complementos, excepciones y reglamentaciones para mejorar su eficacia y hacerlos compatibles con otros derechos y bienes públicos, y que definen su existencia jurídica y contenido concretos. ${ }^{22}$

En el ámbito administrativo, la vinculación positiva de los derechos fundamentales se ha traducido en la fórmula alemana conocida de "organización y procedimiento", ${ }^{23}$ esto es, "que la efectividad de los derechos fundamentales no exige solo respetar la declaración constitucional de derechos, sino que es preciso, además, que existan estructuras públicas, administrativas, a través de las cuales se ejerzan los derechos", ${ }^{24}$ a través de los cuales se hagan verdaderamente efectivos. ${ }^{25}$ En este sentido, la Corte Interamericana de Derechos Humanos, en el caso Velásquez Rodríguez vs. Honduras (1987), indicó que:

21 “Todas las autoridades, en el ámbito de sus competencias, tienen la obligación de promover, respetar, proteger y garantizar los derechos humanos de conformidad con los principios de universalidad, interdependencia, indivisibilidad y progresividad. En consecuencia, el Estado deberá prevenir, investigar, sancionar y reparar las violaciones de los derechos humanos, en los términos que establezca la ley".

22 Derechos fundamentales. Su relación con el poder de policía. [TA]; 10a. Época; TCC; SJF y su Gaceta; Libro XXII, julio de 2013, Tomo 2; p. 1386

23 Cfr. H. H. TRuTE, Die Forschung zwischen grundrechtlicher Freiheit und staatlicher Institutionalisierung, Tübingen, 1994 , pp. 412 y ss.

24 L. M., Díz-Picazo, Sistema de Derechos Fundamentales, op. cit., pp. 129-130.

25 Cfr. P. HäBerle, Grundrechte im Leistungsstaat. Die Dogmatik des Verwaltungsrechts vor den Gegenwartsaufgaben der Verwaltung, Verlag C.H. Beck oHG, p. 56. Cfr. J. M. RodRíguez de Santiago, "La realización del estado social a través de los municipios: servicios públicos locales y asistencia social", 
La obligación de garantizar el libre y pleno ejercicio de los humanos no se agota con la existencia de un orden normativo dirigido a hacer posible el cumplimiento de esta obligación, sino que comporta la necesidad de una conducta gubernamental -organización y procedimiento- que asegure la existencia, en la realidad, de una eficaz garantía del libre ejercicio de los derechos humanos.

En el caso del poder judicial, los mandatos de acción que nacen para los jueces se está manifestando con especial fuerza en el caso del control difuso de convencionalidad, entendiéndose que la obligación que recae sobre ellos consiste en observar los derechos humanos contemplados en nuestro texto constitucional, pero también en los tratados internacionales de los que México es parte.

Para que todas las autoridades cumplan debidamente con los mandatos de acción que los derechos fundamentales representan se ha ideado por parte de la doctrina alemana, principalmente, el denominado principio de "prohibición de defecto" (Untermassverbot), ${ }^{26}$ que se diferencia del clásico principio de proporcionalidad o "prohibición de exceso" (Übermassverbot) en la medida en que, mientras este tiene como función restringir la potestad de las autoridades (principalmente al legislador) para limitar los derechos, aquel impone un mínimo de acción que la autoridad debe satisfacer para proteger esos mismos derechos fundamentales, para que sus medidas sean suficientemente protectoras.

La prohibición de defecto se articula mediante tres subprincipios que se correlacionan, en cierto modo, con los conocidos subprincipios del test de proporcionalidad, estos son: el principio de efectividad, el principio de indispensabilidad y el principio de racionalidad. El principio de efectividad supone que la medida ha de ser adecuada para alcanzar la protección del derecho; el principio de indispensabilidad sirve para medir la suficiencia de la protección desarrollada por el legislador, o sea que no deben existir medidas que respondan a idénticas finalidades pero que consigan una protección mejor; y el principio de racionalidad implica el análisis de la medida de protección y su efectividad en relación con la finalidad perseguida.

En esta tónica, si bien nuestra jurisprudencia todavia no hace suyo este principio de prohibición de defecto, sí que ha reconocido que las autoridades se ven obligadas a realizar conductas positivas determinadas a efectos de garantizar el real ejercicio de los derechos fundamentales y que su omisión significa su transgresión. Así, en una Tesis aislada del Primer Tribunal Colegiado en Materias Administrativa y del Trabajo del Décimo Primer Circuito se señaló que la omisión por parte de la autoridad para garantizar el real ejercicio del derecho fundamental de circulación y la libertad de trabajo del quejoso representaba su violación directa. ${ }^{27}$ En otra

en J. M. Rodríguez de Santiago y J. Ortega Bernardo (coords.), Estado social y municipios: servicios públicos locales y prestaciones asistenciales en España y República Dominicana, 2010, p. 51.

26 K. StERn, Das Staatsrecht der Bundesrepublik Deutschland. Bd. III/2, "Allgemeine Lehren der Grundrechte", C. H. Beck, München, 1994, pp. 761-ss.

$66 \quad 27$ La sentencia señala: "si el quejoso en su demanda de amparo se duele de que las autoridades competentes en la materia han sido omisas en garantizarle el libre ejercicio de las prerrogativas constitucionales de libertad de trabajo y de libre circulación las cuales se encuentran tuteladas en 
Tesis aislada del Pleno de la SCJN se reconoció que "así como debe investigarse la responsabilidad por el exceso de la fuerza, debe investigarse también el incumplimiento de deberes constitucionales y de violación grave de garantías individuales por efecto de ese tipo de omisiones". ${ }^{28}$

\subsection{El efecto irradiación}

Otra consecuencia de concebir a los derechos fundamentales en su acepción objetiva es el denominado efecto irradiación de los derechos, que se refiere al fenómeno mediante el cual los derechos fundamentales permean como principios y valores en todos los sectores del ordenamiento jurídico, en los ámbitos civil, mercantil, fiscal, laboral, entre otros, debiéndose tomar en cuenta al momento de interpretar y aplicar las normas de cada una de estas ramas, aunque es cierto que la incidencia no será la misma en cada una de ellas. ${ }^{29}$

En México, el efecto irradiación de los derechos fundamentales puede observarse directamente en el mismo texto de nuestra Constitución cuando se indica, por ejemplo, que la educación que imparte el Estado fomentará el respeto por los derechos humanos (art. 3 ); cuando se señala que la actuación de las instituciones de seguridad pública se regirá por el respeto de los derechos humanos reconocidos (art. 21); cuando en la fr. X del artículo 89 se indica que la política exterior debe estar orientada al respeto, protección y promoción de los derechos humanos, y cuando se indica, en el artículo 18, que el sistema penitenciario se organizará sobre el respeto de estos derechos, entre otros.

Ligado con este último mandato constitucional, una reciente Tesis aislada del Tercer Tribunal Colegiado en Materia Penal del Segundo Circuito ha señalado que las sanciones disciplinarias dentro un centro de reclusión deben observar

el título concesión para la prestación del servicio público de transporte de pasajeros, toda vez que aquellas toleran el ejercicio por parte de un tercero (particular) de actividades que, por disposición legal, son exclusivas de ellas, resulta evidente que se actualiza una violación a sus derechos fundamentales, pues ello denota la falta de intervención de las referidas autoridades a fin de evitar la citada transgresión, es decir, se trata de una violación directa a la Norma Fundamental por las autoridades responsables e indirecta por el particular". Colisión de derechos fundamentales. Libertad de trabajo y libre circulación. Se violan dichas garantías constitucionales si la autoridad competente en la materia de manera omisiva tolera el ejercicio de actividades por un tercero (particular) que por disposición de la ley le son exclusivas de ella. [TA]; 10a. Época; TCC; SJF y su Gaceta; Libro VI, marzo de 2012, Tomo 2; p. 1081. Véase también la Tesis aislada de rubro: Derechos fundamentales. Obligación de las autoridades de garantizarlos. [TA]; 10a. Época; TCC; SJF y su Gaceta; Libro V, febrero de 2012, Tomo 3; p. 2276.

28 Garantías individuales. El retardo, omisión o incumplimiento de los deberes de las autoridades puede dar lugar a la violación grave de aquellas. [TA]; 9a. Época; Pleno; SJF y su Gaceta; Tomo XXVI, diciembre de 2007; p. 21.

29 Ya en el caso Lüth se señalaba que: "La Ley Fundamental, que no quiere ser neutral frente a los valores, en su título referente a los derechos fundamentales también ha instituido un orden objetivo de valores [...] Este sistema de valores [...] debe regir como decisión constitucional básica en todos los ámbitos del derecho; de él reciben directrices e impulso la legislación, la administración y la jurisdicción. De esa forma influye evidentemente también sobre el derecho civil; ninguna disposición jurídico-civil debe estar en contradicción con él y todas ellas deben interpretarse conforme a su espíritu". 
"la garantía de audiencia", debiendo notificar al reo del inicio del procedimiento sancionador en su contra,

...el cargo que está enfrentando, quién lo ha denunciado y las posibles consecuencias de la sanción, se le deberá de otorgar además un plazo para que prepare su defensa y se le deberá brindar la oportunidad de ofrecer pruebas que respalden su versión de los hechos; así como procurarle la posibilidad de alegar lo que a sus intereses convenga y deberá dictarse una resolución debidamente fundada y motivada; de lo contrario — señala la tesis—, se vulnerarían sus derechos humanos. ${ }^{30}$

En la Tesis aislada de título "Acceso a la información. Criterios que deben observar las restricciones que se establezcan al ejercicio del derecho relativo”, el Cuarto Tribunal Colegiado en materia administrativa del Primer Circuito señaló expresamente al final de su argumentación que los derechos fundamentales han alcanzado un efecto irradiación sobre todo el ordenamiento jurídico, lo que se asocia con su dimensión objetiva, que se traduce en que su contenido informa o permea a este, de manera que si el Texto Fundamental recoge un conjunto de valores y principios, estos irradian al resto del ordenamiento.

Otro claro efecto del efecto irradiación puede observarse también en materia fiscal a partir de la resolución del Primer Tribunal Colegiado en Materia Administrativa del Segundo Circuito en la que señala que los "acuerdos emitidos por el gobernador del Estado de México que concedan subsidios y estímulos fiscales no pueden analizarse a la luz de los principios de justicia fiscal, sino desde una perspectiva más amplia de los derechos fundamentales que la ley suprema establece, como es la de igualdad" ${ }^{31}$ Y otra Tesis en la que se observa el efecto irradiación de los derechos ligado con los mandatos de acción al legislador es aquella que impone la obligación de observar la dignidad humana de las personas afectadas en un juicio familiar. ${ }^{32}$

\subsection{La eficacia horizontal}

Ligada estrechamente al efecto irradiación se encuentra la eficacia horizontal de los derechos fundamentales (Drittwirkung der Grundrechte), que es la teoría construida por H. C. Nipperday (primer magistrado del Tribunal Federal del Trabajo de

30 Corrección disciplinaria a un interno de un centro de reclusión. Previo a su imposición debe otorgarse derecho de audiencia al probable infractor, so pena de vulnerar sus derechos humanos. [TA]; 10a. Época; TCC; SJF y su Gaceta; Libro XXII, julio de 2013, Tomo 2; p. 1365.

31 [TA]; 10a. Época; TCC; SJF y su Gaceta; Libro XVIII, Marzo de 2013, Tomo 3; p. 1902.

32 Derechos humanos en materia familiar. Para su tutela los jueces deben asumir el imperativo que les corresponde como miembros del Estado mexicano, a efecto de respetar la dignidad humana de los sujetos afectados. [TA]; 10a. Época; TCC; SJF y su Gaceta; Libro VIII, mayo de 2012, Tomo 2; p. 1863. Véanse también las Tesis de rubro: Derechos fundamentales. Su dimensión subjetiva y objetiva. [TA]; 10a. Época; 1a. Sala; SJF y su Gaceta; Libro XVI, enero de 2013, Tomo 1; p. 627.

Ya en una jurisprudencia de rubro: Derechos fundamentales. Su vigencia en las relaciones entre particulares, del año 2012, nuestra SCJN indicó que los derechos fundamentales "se traducen en elementos objetivos que informan o permean todo el ordenamiento jurídico”. [J]; 10a. Época; 1a. Sala; SJF y su Gaceta; Libro XIII, octubre de 2012, Tomo 2; p. 798. 
Alemania occidental) que reconoce que los derechos fundamentales no despliegan su eficacia solo frente al poder del Estado (eficacia vertical) como originalmente fueron concebidos, sino que además, despliegan una eficacia frente a los particulares, es decir, de ciudadano a ciudadano. ${ }^{33} \mathrm{Y}$ es que si la dignidad y la libertad de la persona constituyen la base del Estado, su observancia obliga no solo a los poderes públicos, sino a todas las personas.

$\mathrm{Su}$ reconocimiento quedó manifiesto en la ya citada sentencia Lüth del Tribunal Constitucional Federal de Alemania, en la que se consideró que la sentencia del juez ordinario vulneraba el derecho fundamental a la libertad de expresión del señor Lüth toda vez que el juez se encontraba vinculado por los derechos fundamentales y debía tenerlos en cuenta a la hora de interpretar y aplicar las normas de derecho privado; al no valorar en su justa medida el efecto de un determinado derecho fundamental en una relación privada, el juez incurrió en su vulneración.

Es un hecho que los derechos fundamentales surten efectos en las relaciones particulares. Para nadie pasa desapercibido que los derechos fundamentales se desarrollan en el seno de la sociedad y que afectan de forma habitual las relaciones civiles, mercantiles, laborales y, en general, la vida social de las personas. ${ }^{34}$ Y es que no tendría ningún sentido hablar de un derecho de libertad o de igualdad contra el Estado, si la verdad es que la libertad, la igualdad y casi todos los derechos fundamentales se desenvuelven en el marco de las relaciones sociales. Como afirma Naranjo de la Cruz, si las libertades no se ostentan frente a los particulares, nunca podrán ser reales, ni mucho menos efectivas. ${ }^{35}$

Es cierto, no obstante, que como sostiene H. C. Nipperdey, la eficacia horizontal no es predicable de todos los derechos, por lo que en cada caso, habrá que analizar si procede o no hablar de ella, ${ }^{36}$ aunque no por eso, la proyección horizontal de los derechos es descartable. Será la delimitación del ámbito protegido por cada derecho fundamental lo que indique si despliega o no sus efectos en las relaciones particulares y, en su caso, hasta dónde llegue dicha eficacia. ${ }^{37}$ Hay derechos que por su propia naturaleza despliegan más una eficacia frente a terceros que frente al Estado, como es el caso de los derechos de la personalidad (honor, intimidad e imagen) que colisionan directamente con la libertad de expresión y el derecho a la información de otras personas; el derecho de reunión y manifestación se ostenta no solo frente a las autoridades públicas sino también, y principalmente, frente a otros particulares que ven limitada su libertad de circulación; el derecho de asociación se ostenta la mayoría de las veces frente a las asociaciones a las que

33 R. Alexy, Teoría de los derechos fundamentales, op. cit., p. 468.

34 M. L. Balaguer Callejón, Interpretación de la Constitución y ordenamiento jurídico, Madrid, Tecnos, 1997, p. 45.

35 R. NARANJo DE LA CRUz, Los límites de los derechos fundamentales en las relaciones particulares, op. cit., p. 201.

36 H. C. Nipperderdey, Freie Entfaltung der Persönlichkeit, Die Grundrechte, IV, 2, Berlin, Dunker \& Humblot, 1962, p. 752.

37 R. NARANJO DE LA CRUZ, Los límites de los derechos fundamentales en las relaciones entre particulares, op. cit., pp. 204 y 205. 
se pertenece; y ni qué decir de los derechos laborales de sindicación y huelga que constituyen un limite a la libertad de empresa.

Por el contrario, existen otros derechos fundamentales que son oponibles, en principio, solo frente al Estado, como suele ocurrir con los derechos de seguridad jurídica, el debido proceso judicial, la garantía de irretroactividad de la ley, el derecho a la exacta aplicación de la ley penal, los derechos de los legalmente privados de la libertad, el derecho a la administración de justicia por parte de tribunales previos y determinados por ley, el derecho a la readaptación social del delincuente, o los derechos de los acusados y de los procesados.

Pero en realidad, lo que se ha discutido de la eficacia horizontal de los derechos no ha sido tanto si surten sus efectos frente a particulares, sino la forma en que lo han de hacer, $y$, al respecto, la doctrina se ha enfrascado en una discusión un tanto acalorada entre dos corrientes principales: la teoría de la eficacia horizontal mediata y la teoría de la eficacia horizontal inmediata.

La teoria de la eficacia horizontal mediata, cuyo principal representante fue G. Dürig, ${ }^{38}$ trata de ser fiel al origen histórico de los derechos fundamentales como limites al poder del Estado y considera, en consecuencia, que los derechos deben permanecer con esta naturaleza y esta finalidad, ya que extender sus efectos a las relaciones particulares seria desvirtuar su origen. A esta postura le preocupa también la autonomia de la voluntad de los particulares y considera que si los individuos pudieran invocar directamente sus derechos fundamentales en los compromisos que han asumido a través de pactos privados, ${ }^{39}$ se atentaría contra la autonomía de la voluntad, alterando la estructura del ordenamiento jurídico privado. ${ }^{40}$

Sin embargo, esta corriente no niega que los derechos fundamentales surten efectos en las relaciones particulares, que la vida, la libertad, la integridad, la privacidad,

38 T. Maunz y G. DüriG, Grundgesetz Kommentar, Band, V, Lfg. 20, marginal 29, p. 102.

39 U. Scheuner, "Fundamental rights and the protection of the individual against social groups and powers in the constitutional system of the Federal Republic of Germany”, en Amicorum Discipulorumque Liber René Cassin III, Protection des Droits de l'Homme dans les Rapports Entre Personnes Privées, Paris, Pédone, 1971, p. 265.

40 CANARIs, en contraposición a la teoría de la eficacia inmediata, sostiene que: "la presencia de un poder social no constituye un problema independiente, sino que se inscribe dentro de la cuestión, mucho más amplia, de la vulneración de la paridad contractual, para cuya solución el derecho facilita un gran número de instrumentos (desde los mecanismos clásicos del derecho privado dirigidos a garantizar la autonomía de las partes, hasta la protección de la competencia o la regulación de los derechos de los consumidores pasando por los convenios colectivos). En consecuencia, no resulta necesario (ni aconsejable) recurrir a una aplicación directa de los derechos fundamentales" (C. W. Canaris, "Grundrechte und Privatrecht", Archiv für die civilistische Praxis, 3, 1984, p. 207). No obstante, al defender la autonomía de la voluntad de las partes, tampoco debemos olvidar que, como dice Hesse, "un derecho civil que descansa sobra la protección de la personalidad y sobre la autonomía privada forma parte de las condiciones fundamentales del orden constitucional de la Ley Fundamental. La libertad privada de la persona, que el derecho civil presupone y para cuya salvaguardia y desarrollo dispone normas y procesos jurídicos, es requisito indispensable para las decisiones responsables y para la posibilidad misma de decidir. Y esta última sustenta a su vez el libre desarrollo de la personalidad recogido como derecho fundamental en la constitución” (K. Hesse, Derecho constitucional y derecho privado, Madrid, Civitas, trad. de I. Gutiérrez, 1995, p. 86). 
la libertad de expresión y otros derechos fundamentales surten sus efectos frente a terceros; y como los derechos fundamentales son principios y valores de todo el ordenamiento jurídico, el Estado tiene la obligación de garantizar su protección en las relaciones particulares.

Debido a lo anterior, esta teoría considera que la eficacia que surten los derechos fundamentales frente a terceros es considerándolos siempre como principios y valores del ordenamiento jurídico, ${ }^{41}$ y para su concreción en las relaciones particulares es necesario que el Estado determine esta eficacia a través de sus órganos. ${ }^{42} \mathrm{El}$ órgano público a través del cual el Estado responde con su mandato constitucional de proteger los derechos fundamentales garantizando los valores y bienes jurídicos que ellos representan es el legislativo; ${ }^{43}$ lo que obedece a la legitimidad democrática que posee en tanto es el representante de la soberanía nacional. ${ }^{44}$ Según H. H. Klein, "solo a través de la ley o sobre la base de una ley el Estado se encuentra facultado para combatir activamente las conductas privadas que suponen una amenaza para un bien jurídico". ${ }^{45}$ La forma en que el legislador concretizará la eficacia horizontal de los derechos fundamentales será tomando en cuenta los valores objetivos que estos representan y los adaptará a la propia estructura de las relaciones privadas debiendo moverse entre el contenido esencial de los derechos y la garantía de la autonomía privada. ${ }^{46}$

Lo cierto es que como el legislador no puede prever todas las circunstancias en que los derechos fundamentales surten sus efectos en las relaciones particulares o pueden existir imprecisiones, el juez, de manera subsidiaria, resolverá los conflictos de derechos fundamentales que se susciten entre particulares concibiéndolos como principios y valores objetivos. ${ }^{47}$

Desde esta perspectiva, quien en realidad está constreñido por los derechos fundamentales es el poder público y no el particular. En todo caso, si este último se encuentra vinculado es en la medida en que los derechos son decisiones valorativas objetivas (objektive Wertentscheidungen) y no derechos subjetivos que ostente frente a otro particular.

Esta postura ha llevado a T. Quadra-Salcedo a afirmar que los derechos fundamentales se han degradado,

41 Ver al respecto T. Maunz y G. Dürig, Grundgesetz Kommentar, Band, V, Lfg. 20, marginal 29, p. 102.

42 T. QuAdRA-SAlcedo, El recurso de amparo y los derechos fundamentales en las relaciones particulares, Madrid, 1981, p. 51.

43 Véase C. W. CANaris, Grundrechte und Privatrecht, op. cit., p. 225.

44 T. Quadra-Salcedo, El recurso de amparo, op. cit., p. 52.

45 H. H. KLeIn, Die grundrechtliche Schutzpflicht, Deutsches Verwaltungsblatt 9 (1994), p. 491. CRUZ Villalón, de igual forma, cree que: "es [...] el legislador el llamado a determinar, en la medida de lo posible, cuáles son las consecuencias que para las relaciones entre particulares se derivan del hecho de que la Constitución haya reconocido como derechos fundamentales, por ejemplo, la libertad de expresión, el derecho a la intimidad o el principio de igualdad". Pedro Cruz Villalón, "Formación y evolución de los derechos fundamentales”, en Revista Española de Derecho Constitucional 9, 25 (1989), pp. 35-62.

46 J. M. Bilbao Ubillos, La eficacia de los derechos fundamentales frente a particulares, Madrid, Centro de Estudios Políticos y Constitucionales, 1997, p. 290 y 291.

47 T. Quadra-SAlcedo, El recurso de amparo, op. cit., pp. 53 y 54. 
...en el sentido de que han dejado de configurarse como derechos subjetivos perfectamente delimitados y oponibles frente a todos para transformarse en simples valores y principios objetivos de los que nadie es titular concreto como para poderlos exigir como si de un derecho se tratase; o si se quiere decir de otra manera: porque no aparecen claramente delimitados y exigen una concreción judicial se piensa que ya no son derechos subjetivos, sino meros valores objetivos..$^{48}$

Por su parte, J. M. Bilbao Ubillos ha dicho que esta teoría de la eficacia mediata a través del juez es en realidad "ilusoria", ${ }^{49}$ pues desde una perspectiva práctica, no importa cuál ha sido el método de solución del juez, sino que el afectado se vea o no resarcido en la violación de su derecho fundamental, ya sea que el juez haya considerado que la violación atenta contra un valor objetivo o que se haya violado un verdadero derecho subjetivo. En el fondo, lo que se defiende es un derecho subjetivo de la persona. ${ }^{50}$ Además, este autor no ve ninguna diferencia entre la eficacia horizontal mediata con intervención del juez y el principio general de interpretación de todas las normas del ordenamiento conforme a la Constitución. ${ }^{51}$

Por otro lado, el mismo J. M. Bilbao Ubillos señala agudamente que:

...para concretar el alcance de un derecho fundamental cuando el conflicto se suscita en el ámbito de las relaciones jurídico-públicas, también es necesaria la mediación judicial y no por eso su eficacia es mediata, ni la interpretación que hace el juez es desde una óptica del derecho como un valor objetivo. ${ }^{52}$

Por lo demás, al defender esta postura se estaría concibiendo a los derechos fundamentales en las relaciones particulares, ya no como derechos constitucionales, sino legales. ${ }^{53}$

Por su parte, la teoría de la eficacia horizontal inmediata sostiene que los derechos fundamentales surten sus efectos en las relaciones particulares, no como valores y principios del ordenamiento jurídico, sino como verdaderos derechos subjetivos. Y no es que se niegue la dimensión objetiva de los derechos fundamentales, pero considera que en las relaciones particulares estos no se ostentan como tales.

En tanto se considera que los derechos fundamentales son verdaderos derechos subjetivos exigibles directamente por una persona frente a la otra, es innecesaria la mediación de un órgano estatal para su concreción. No se niega que la ley sea el medio idóneo para la configuración de los derechos fundamentales (tanto en las relaciones públicas, como en las privadas) pero resulta dificil sostener que su

$48 \quad$ Idem, pp. 54 y 55.

49 J. M. Bilbao Ubillos, La eficacia de los derechos fundamentales, op. cit., p. 318.

50 En el caso Lüth, por ejemplo, si bien la solución que se dio se debió a que según el Tribunal Constitucional, el juez ordinario no contempló la normativa civil desde la perspectiva de los valores que los derechos fundamentales representaban, lo que importó para el señor Lüth fue que la violación de su derecho fundamental fue reconocido y el daño resarcido.

51 J. M. Bilbao Ubillos, La eficacia de los derechos fundamentales, op. cit., p. 313.

52 Idem, p. 321.

53 Idem, p. 297. 
operatividad en las relaciones particulares dependa única y exclusivamente de la voluntad del legislador, pues este no puede contemplar todas las situaciones ni todos los conflictos existentes. ${ }^{54} \mathrm{El}$ mismo Böckenferde, defensor de la eficacia mediata, ha dicho que la realización de los derechos fundamentales, "no puede depender de una configuración infra-constitucional suficiente del Ordenamiento jurídico privado". ${ }^{55}$ La obligación de respetar los derechos fundamentales por los ciudadanos surge y emana directamente de la Constitución y no de las normas de desarrollo de esta. ${ }^{56}$

Es innegable que, si existe una ley que regule la eficacia de un derecho fundamental en una determinada relación privada, el conflicto deberá resolverse según lo previsto en dicha norma, pero si no hay un precepto específico que permita solucionar el caso concreto, el derecho fundamental que se pretende defender y que está recogido en la Constitución es vinculante directamente como un derecho subjetivo de una parte frente a la otra, y no como un criterio hermenéutico al que se deba recurrir para descifrar su influencia en el derecho privado. ${ }^{57}$

A nuestro entender, el desarrollo legislativo no debe ser necesario para configurar la eficacia horizontal de los derechos fundamentales, como no lo es para su eficacia vertical. En otras palabras, si los derechos fundamentales son vinculantes frente al Estado de manera directa, sin necesidad de previsión legal, ¿por qué es necesario que haya una ley que los configure en las relaciones particulares? ${ }^{58}$

En México, la eficacia horizontal de los derechos humanos no está reconocida expresamente en el texto constitucional. Ni siquiera con la reforma de 2011 se incorporó algún artículo en el que se reconociera de manera expresa, como sí lo hace la Constitución de Portugal de 1976 en su artículo 18.1, que reza: "los preceptos relativos a los derechos, libertades y garantías son directamente aplicables a las entidades públicas y privadas y vinculan a estas"; o como la Constitución colombiana de 1991, en cuyo numeral 86 establece la acción de tutela como medio de protección ante la violación de los derechos fundamentales cometida por la autoridad pública o por particulares.

No obstante lo anterior, la eficacia horizontal de los derechos fundamentales se ha empezado a reconocer ya en varias resoluciones judiciales. Una clara explicación de este fenómeno se ofrece, por ejemplo, en la Tesis aislada de rubro: "Derechos

54 Idem, p. 295; ver también la STC 112/1989 FJ 2º, de 19 de junio, en la que el Tribunal Constitucional reconoció que la intervención del legislador no siempre es necesaria.

55 E. W. BöcKENFÖRDE, Sobre la situación de la dogmática de los derechos fundamentales tras 40 años de Ley Fundamental, op. cit., p. 113.

56 T. Quadra-Salcedo, El recurso de amparo, op. cit., p. 70.

57 En el mismo sentido véase M. Venegas Grau, Derechos fundamentales y derecho privado, op. cit., pp. 198 y 199.

58 Coincidimos con Bilbao Ubillos en que la intervención del legislador no es un trámite indispensable (como no lo es en el campo de la relaciones individuo-Estado). "No parece compatible la afirmación de que los derechos fundamentales solo operan (frente a particulares) cuando el legislador así lo decide" (J. M. Bilbao Ubillos, La eficacia de los derechos fundamentales frente a particulares, op. cit., p. 297). 
fundamentales. Son susceptibles de analizarse, vía amparo directo interpuesto contra la sentencia definitiva que puso fin al juicio, en interpretación directa de la constitución, aun cuando se trate de actos de particulares en relaciones horizontales o de coordinación". ${ }^{59}$

Además, en la Tesis jurisprudencial de rubro "Derechos fundamentales. Su vigencia en las relaciones entre particulares", ${ }^{60}$ la Primera Sala reconoce la dimensión objetiva de los derechos fundamentales y, a partir de esta, desprende su eficacia horizontal. Sin embargo, la misma sentencia aclara, como lo hemos hecho en párrafos anteriores, que la eficacia horizontal no se puede predicar de manera general respecto de todos los derechos fundamentales, "en virtud de que en estas relaciones, a diferencia de las que se entablan frente al Estado, normalmente encontramos a otro titular de derechos, lo que provoca una colisión de los mismos y la necesaria ponderación por parte del intérprete".

En un caso de sucesión agraria se resolvió también que, aunque la designación de sucesores constituye un acto jurídico unilateral, al que le es aplicable la teoría de la libertad de la voluntad, también es cierto que dicha facultad no puede generar situaciones de exclusión que afectan los derechos fundamentales, y señala la sentencia que las normas de Derecho privado y las constitucionales suponen una relación estrecha que vincula tanto al Estado como a los particulares, de manera que aquel debe imponer su sanción judicial y reparar el daño causado, porque el catálogo de derechos fundamentales - ya sea que derive de la Constitución o se reconozca en una convención internacional - tiene aplicación en las relaciones entre particulares, por virtud de que tales derechos tienen no solo "efecto vertical", sino también "horizontal" ${ }^{61}$ Como puede observarse, esta sentencia reconoce al mismo tiempo la eficacia horizontal de los derechos fundamentales, el efecto irradiación y los mandatos de acción que vinculan en este caso al juzgador.

En otra resolución, una Tesis aislada de la Primera Sala de la SCJN reconoció que el derecho a la igualdad y a la no discriminación goza de eficacia no solo frente al poder del Estado, sino también en las relaciones particulares, y se señala la obligación para el juzgador de "analizar las relaciones jurídicas en las que los derechos fundamentales se ven confrontados con otros bienes o derechos constitucionalmente protegidos, a efecto de determinar cuáles derechos son solo oponibles frente al Estado y cuáles otros gozan de la referida multidireccionalidad”. ${ }^{2}$

59 [TA]; 9a. Época; TCC; SJF y su Gaceta; Tomo XXX, agosto de 2009; p. 1597.

60 Derechos fundamentales. Su vigencia en las relaciones entre particulares. [J]; 10a. Época; 1a. Sala; SJF y su Gaceta; Libro XIII, octubre de 2012, Tomo 2; p. 798.

61 La sentencia tiene por rubro: Sucesión en materia agraria. Aun cuando le es aplicable la teoría de la libertad de la voluntad, cuando genera situaciones de exclusión que afectan los derechos fundamentales, no debe desvincularse de la teoría de la eficacia horizontal de estos. [TA]; Amparo directo 707/2009. Agustín Roque Ortega. 18 de febrero de 2010. Unanimidad de votos. Ponente: Victorino

62 Derechos fundamentales de igualdad y de no discriminación. Gozan de eficacia en las relaciones entre particulares. [TA]; 10a. Época; 1a. Sala; SJF y su Gaceta; Libro XVI, enero de 2013, Tomo 1; p. 627. 
Y en otra de sus Tesis, la misma Primera Sala de la SCJN añade que esta eficacia horizontal de los derechos fundamentales es reconocida también respecto de los derechos contenidos en tratados internacionales, y es que, como sostiene la resolución, esta eficacia "deriva del contenido del derecho y no de la forma en que el mismo se incorpora al sistema jurídico". ${ }^{63}$

Por último, también una Tesis aislada del Primer Tribunal Colegiado en Materias Administrativa y de Trabajo del Décimo Primer Circuito ${ }^{64}$ ha reconocido la eficacia horizontal de los derechos fundamentales y parece acogerse a una interpretación inmediata de esta toda vez que para el Tribunal:

...el acto de un particular por el que se crea el Derecho privado no escapa a los controles de constitucionalidad y de convencionalidad, pues aun cuando está sujeto a la teoría de la voluntad de las partes tiene un límite, y ese límite son los derechos humanos, oponibles no solo a los poderes públicos sino también a los particulares.

Y más adelante señala que "si al Estado se le exige respeto a tales derechos, no hay razón para que el particular no los respete frente a otro particular”. Esta concepción hace pensar que el juzgador entiende a los derechos fundamentales como verdaderos derechos subjetivos en las relaciones privadas y no tanto como principios y valores del ordenamiento jurídico.

\subsection{La asunción judicial en México}

Parece innegable que los derechos fundamentales surten efectos frente particulares, ya sea que se les conciba como principios y valores o como verdaderos derechos subjetivos. Pero la verdadera problemática de esta teoría no es tanto sustantiva sino adjetiva, el problema es procesal y consiste en encontrar el proceso idóneo que proteja los derechos fundamentales de las personas en sus relaciones particulares.

Como se sabe, el medio procesal a través del cual se protegen los derechos fundamentales en nuestro país, como en muchos otros, es el Juicio de Amparo; pero como es también sabido, este resulta improcedente contra actos de particulares. Si bien la nueva Ley de Amparo reconoce en su artículo 5, fracción segunda, que los particulares tendrán la calidad de autoridad responsable para efectos de este juicio, lo serán cuando realicen "actos equivalentes a los de autoridad, que afecten derechos en los términos de esta fracción, y cuyas funciones estén determinadas por una norma general". Estas condiciones, como ya puede advertirse, en realidad siguen haciendo inviable la promoción de un juicio de amparo contra la violación de los derechos fundamentales que provenga de particulares.

63 Derechos fundamentales contenidos en tratados internacionales. Gozan de eficacia en las relaciones entre particulares. [TA]; 10a. Época; 1a. Sala; SJF y su Gaceta; Libro XVII, febrero de 2013, Tomo 1; p. 799.

64 Derechos humanos. Constituyen un límite a la autonomía de la voluntad, y son oponibles frente a particulares en un plano de horizontalidad. [TA]; 10a. Época; TCC; SJF y su Gaceta; Libro XII, septiembre de 2012, Tomo 3; p. 1723. 
Que el juicio de amparo no proceda contra actos de particulares ocurre también en otros países, y por esta razón se ha acudido a una ficción jurídica denominada teoría de la asunción judicial. Esta teoría, aunque no ha sido llamada así en nuestro país, parece ser la solución que han adoptado nuestros tribunales para proteger la violación de los derechos fundamentales en las relaciones particulares, pero antes de entrar en ellas, vale la pena estudiar esta teoría.

La asunción judicial consiste en imputar la violación de un derecho fundamental que tuvo su origen en una relación privada al poder judicial. Todo conflicto entre particulares es alegable ante los tribunales ordinarios, que son parte del poder público y se encuentran vinculados a los derechos fundamentales, no solo en un sentido negativo, sino también mediante un deber de protección. Por esta razón, se entiende que si en su actuar un juez no protege debidamente un derecho fundamental, lo ha violado, y su resolución, en tanto actuación del Estado, es recurrible en amparo ante el órgano judicial inmediato superior. ${ }^{65} \mathrm{El}$ órgano judicial superior conocerá del recurso y declarará, si así lo considera, la nulidad del acto judicial por haber transgredido el derecho en cuestión, en tanto que no lo protegió, obligando al órgano judicial a reparar dicha violación, ${ }^{66}$ y así en última instancia se reparará la violación del derecho fundamental que se cometió en una relación privada.

La asunción judicial supone la obligación de jueces y tribunales ordinarios de prestar una protección efectiva a los derechos fundamentales frente a violaciones cometidas por sujetos privados. ${ }^{67}$ Se imputa la violación de un derecho al órgano judicial en la medida en que, a juicio del perjudicado, no se reparó la infracción sometida a su conocimiento. ${ }^{68}$

65 GuAdra-SALCEdo explica la teoría de la asunción judicial en los siguientes términos: "puesto que todo conflicto entre particulares puede acceder libremente a los Tribunales ordinarios y estos son parte de los poderes públicos del poder judicial, las decisiones de los Tribunales, si se entiende que no protegen adecuadamente y correctamente los derechos y libertades, pueden ser recurridas ante el Tribunal Constitucional por la vía de amparo, puesto que aquí ya tenemos un acto del poder público que ha desconocido un derecho fundamental. Por este medio podrían acceder al TC todas las violaciones de derechos fundamentales originadas en las relaciones entre particulares y formalizadas procesalmente ante un Tribunal" (T. GUADRA-SAlcEDo, El recurso de amparo y los derechos fundamentales en las relaciones entre particulares, op. cit., pp. 14 y 15); por su parte, García MuRILLO es muy claro cuando dice: "los ciudadanos están sujetos a la Constitución y, por tanto, a los derechos fundamentales, que tienen obligación de respetar; los jueces y tribunales, por su parte, están obligados a respetar los derechos fundamentales, de suerte que el incumplimiento, por parte de los particulares, de su obligación de respetarlos puede dar lugar a una acción sin pretensión de tutela o reparación ante los órganos jurisdiccionales; por último, el eventual incumplimiento por los órganos judiciales de su obligación de amparar el derecho permite acudir al amparo constitucional (J. García Murillo, La protección judicial de los derechos fundamentales, op. cit., p. 201). GARCíA TORRES y JimÉnEZ-BlAnCo son todavía más concretos: “todas las controversias sobre derechos de los particulares son residenciables ante el juez; y el juez es, ahora ya sin duda, un poder público que puede violar derechos fundamentales y por tanto se justifica un recurso de amparo ante el Tribunal Constitucional" (J. García Torres y A. Jiménez-Blanco, Derechos fundamentales y relaciones entre particulares, op. cit., p. 37).

66 J. García Torres y A. Jiménez-Blanco, Derechos fundamentales y relaciones entre particulares, op. cit., p. 84. ción del derecho fundamental es porque el derecho fundamental debia ser protegido, lo que es tan- 
El origen de la asunción judicial se remonta otra vez al caso Lüth, en el que el Tribunal de Karlsruhe consideró que el juez ordinario no tomó en cuenta el efecto irradiación de los derechos fundamentales en las relaciones privadas, incurriendo así en su vulneración, y al ser la resolución judicial un acto del poder público, se pudo impugnar ante el Tribunal Constitucional Alemán. ${ }^{69}$

En España, el Tribunal Constitucional ha adoptado esta solución en numerosas ocasiones, pero el que se considera el caso Lüth español, según J. García Torres y A. Jiménez-Blanco ${ }^{70}$ es la Sentencia 18/1984 en la que el Tribunal Constitucional de ese país señala que:

La sujeción de los poderes públicos a la Constitución (art. 9.1) se traduce en un deber positivo de dar efectividad a tales derechos en cuanto a su vigencia en la vida social, deber que afecta al legislador, al ejecutivo y a los Jueces y Tribunales, en el ámbito de sus funciones respectivas. De donde resulta que el recurso de amparo se configura como un remedio subsidiario de protección de los derechos y libertades fundamentales, cuando los poderes públicos han violado tal deber.

Aunque según J. M. Bilbao Ubillos ${ }^{71}$ la sentencia con la que el Tribunal Constitucional ha alcanzado su madurez en este tema es la 55/1983 de 22 de junio, que en su F.J. 5․ afirma: "Entiende esta Sala (la Segunda) que, cuando se ha pretendido judicialmente la corrección de los efectos de una lesión de tales derechos (fundamentales) y la sentencia no ha entrado a conocerla [...], es la sentencia la que entonces vulnera el derecho fundamental en cuestión". ${ }^{72}$

to como dar por supuesto que debía ser canon de valoración y pauta de medida en las relaciones entre particulares. [...] Aunque el déficit de protección del derecho sea imputable al juez, 'la lógica obliga a aceptar que la lesión inicial u originaria del derecho se produjo en la relación Inter privatos" (J. GARcía ToRREs, "Reflexiones sobre la eficacia vinculante de los derechos fundamentales", en Poder Judicial 19, 1988, p. 28).

69 El caso Lüth puede ser analizado desde dos perspectivas: en sentido sustancial o de fondo, en la medida en que el Tribunal Constitucional alemán adoptó la teoría de la mittelbare Drittwirkung para reconocer de alguna forma la eficacia horizontal de los derechos fundamentales; y en sentido adjetivo o procesal, para apreciar que el Tribunal Constitucional recurrió a la teoría de la asunción judicial como el instrumento procesal a través del cual pudo entrar a conocer el caso en cuestión.

70 J. García Torres y A. Jiménez-Blanco, Derechos fundamentales y relaciones entre particulares, op. cit., p. 87.

71 J. M. Bilbao Ubillos, La eficacia de los derechos fundamentales frente a particulares, op. cit., p. 152.

72 También es muy clara la STC 51/1988 de 22 de marzo FJ 1 o al señalar que: "por las exigencias técnico procesales referidas el recurso de amparo solo es viable si en caso de lesión de la libertad sindical por persona o entidad privada, media un acto judicial que no repare las lesiones supuestamente verificadas". De igual forma, la STC 171/1990 de 12 de noviembre FJ 4º, señala: "cuando se ejerce una acción civil para protección del bien jurídico honor o intimidad frente al ejercicio del derecho reconocido en el art. $20 \mathrm{CE}$ la decisión judicial ha de fundarse necesariamente en una determinada concepción de estos bienes y derechos y de su recíproca relación. Si esta concepción no es la constitucionalmente adecuada, la decisión judicial, como acto del poder público, habrá de reputarse lesiva de uno u otro derecho fundamental, sea por haber considerado ilícito su ejercicio, sea por no haberle otorgado la protección que debería otorgarle". La STC 178/1993 de 31 de mayo FJ $2^{\circ}$, dice: "la función del Tribunal en este tipo de recursos consiste en dilucidar si la ponderación judicial de los derechos en presencia ha sido realizada de modo que se respete su correcta valoración y definición constitucional". 
En México, la teoria de la asunción judicial parece ser también la forma en que se protege y se ha protegido o resarcido la violación de los derechos fundamentales en las relaciones inter privatos. Ya hemos señalado que prácticamente el juicio de amparo sigue siendo improcedente en contra de actos emitidos por particulares. La SCJN ha ratificado a lo largo de los años aquella postura que fortalecía la improcedencia del juicio de amparo contra actos de particulares, como en aquella de rubro: "Amparo improcedente (controversias entre particulares)", en la que senalaba expresamente que:

Si los conceptos de violación se enderezan exclusivamente a sostener la existencia de ciertos derechos provenientes de pactos contractuales entre particulares, su desconocimiento por una de las partes, no es un acto decisivo, ni da lugar a ejercitar, en forma directa, el juicio de amparo, sin que previamente se decida en controversia ante las autoridades competentes, sobre dichos derechos. ${ }^{73}$

De igual forma, en la Tesis aislada de rubro "Autoridad para los efectos del amparo. Tiene ese carácter un órgano del Estado que afecta la esfera jurídica del gobernado en relaciones jurídicas que no se entablan entre particulares", se señala claramente que la autoridad, para efectos del juicio de amparo, "no debe tratarse de un particular, sino de un órgano del Estado que unilateralmente impone su voluntad en relaciones de supra o subordinación, regidas por el derecho público, afectando la esfera jurídica del gobernado". ${ }^{74}$

Pero como señalan J. N. Silva Meza y F. Silva García, en México los derechos fundamentales sí han sido protegidos en las relaciones particulares de manera indirecta $^{75}$ (que no debe confundirse con la eficacia horizontal indirecta o mediata) cuando el agraviado demanda o denuncia a un particular en la vía ordinaria correspondiente, ya sea penal, civil, mercantil, familiar, laboral conforme a las causales de ilegalidad o nulidad referentes de la ley de la materia y en caso de no recibir sentencia favorable demanda en amparo directo al juzgador por la violación a los artículos 14 y 16 de la CPEUM.

En efecto, desde que se abrió la posibilidad de que el amparo procediera contra actos del poder judicial, con el caso Miguel Vega, estos han procedido contra las violaciones cometidas por el juzgador en contra de las garantias del debido proceso contenidas entre otros, en los artículos 14 y 16 de nuestra Constitución, cuando quizá el origen de la litis hubiera sido la violación de un derecho fundamental en

73 Número de registro: 321,865. Tesis aislada. Matria(s): común. Quinta época. Instancia: Segunda sala. Fuente: Seminario Judicial de la Federación. Tomo LXXXIX. Tesis: p. 3156. Amparo administrativo en revisión 5892/46. Camiones de Celestún, S.C.L. 26 de septiembre de 1946. Unanimidad de cuatro votos. Ausente: Alfonso Francisco Ramírez. La publicación no menciona el nombre del ponente.

74 Número de registro: 194,367. Tesis aislada. Materia(s): Administrativa. Novena Época. Instancia Segunda Sala. Fuente. Seminario Judicial de la Federación y su Gaceta. Tomo IX, marzo 1999. Tesis: 2a. XXXVI/99. p. 307. Contradicción de tesis 71/98. Entre la sustentada por el Tercer y el Sexto Tribunales Colegiados en Materia Administrativa del Primer Circuito. 19 de febrero 1999. Unanimidad de cuatro votos. Ausente: José Vicente Aguinaco Alemán. Ponente: Mariano Azuela Güitrón. Secretario: Ariel Albero Rojas Caballero.

75 J. N. Silva Meza y F. Silva García, Derechos fundamentales, México, Porrúa, 2013, p. 148.

DÍKAION - ISSN 0120-8942 - EISSN 2027-5366 
una relación jurídica entre particulares. ${ }^{76}$ Pero con la reforma de 2011 , el juzgador, en tanto autoridad, está obligado a velar por todos los derechos fundamentales en todas las relaciones privadas, por lo que ahora el amparo directo procede no solo por la violación de los artículos 14 y 16 CPEUM, sino por la inobservancia o la tutela deficiente por parte del juzgador de cualquier derecho fundamental que haya sido transgredido en una relación jurídica particular. ${ }^{77}$

Precisamente por ello, la SCJN ha reconocido que el amparo directo es la vía idónea para proteger la violación de los derechos fundamentales en las relaciones particulares. Así, en su resolución de rubro: "Amparo directo. Resulta la vía adecuada para que los tribunales colegiados de circuito conozcan de aquellas sentencias de los tribunales ordinarios que desconozcan una violación de derechos fundamentales cometida por un particular", ${ }^{78}$ la Primera Sala de la SCJN señala precisamente la obligación de los tribunales para proteger los derechos fundamentales en las relaciones particulares en tanto "principios objetivos del ordenamiento jurídico mexicano", y que por la omisión o desprotección por parte de estos, procederá el amparo directo ante los Tribunales Colegiados de Circuito. Pero los tribunales obligados a velar por los derechos fundamentales no solo son los ordinarios sino también los colegiados, y puede darse el supuesto de que estos también transgredan por su omisión o inobservancia los derechos fundamentales de algunas de las partes. Por esta razón, la Primera Sala de la SCJN ha señalado en otra Tesis aislada, ${ }^{79}$ que ella (la Suprema Corte de Justicia de la Nación) puede conocer, a través de la revisión en amparo directo, de aquellas sentencias de los Tribunales Colegiados de Circuito que no atiendan a la función de los derechos fundamentales como principios objetivos del ordenamiento jurídico mexicano.

Estas dos Tesis, aunque sean breves, representan una gran aportación hacia la consolidación de la jurisprudencia constitucional en materia de eficacia horizontal de derechos fundamentales, y esto es así por dos razones; en primer lugar, porque al hacer mención, ambas tesis, a los derechos fundamentales como principios

76 Véanse entre otras muchas la Tesis aislada de rubro: Salario. Comprende las gratificaciones anuales, en la que precisamente se señaló que la Junta violó la exacta aplicación de la ley consagrada en los artículos 14 y 16 CPEUM. Localización: [TA]; 6a. Época; 4a. Sala; SJF; Volumen LXXXVIII, Quinta Parte; p. 27. Registro 162 465. Sentencias en el sistema de justicia penal acusatorio. Deben emitirse en forma escrita y estar documentadas en congruencia con los artículos 14, 16, 20 y 133 de la Constitución federal y 2, inciso c, 47, 65, 66 y 393 del código de procedimientos penales para el Estado de México. Localización: [TA]; 9a. Época; TCC; SJF y su Gaceta; Tomo XXXIII, marzo de 2011; p. 2459. II.2o.P.255 P.; Registro 176453 Sentencia definitiva en materia penal. Si al dictarla la autoridad judicial analiza únicamente el cuerpo del delito y omite el estudio de los demás elementos del tipo, de la antijuridicidad y la culpabilidad viola los artículos 14, 16 y 17 de la constitución federal, Localización: [TA]; 9a. Época; TCC; SJF y su Gaceta; Tomo XXII, diciembre de 2005; p. 2764. I.7o. 72 P.

77 En este sentido véase la Tesis de rubro: Garantías individuales. El retardo, omisión o incumplimiento de los deberes de las autoridades puede dar lugar a la violación grave de aquellas. [TA]; 9a. Época; Pleno; SJF y su Gaceta; Tomo XXVI, diciembre de 2007; p. 21.

78 [TA]; 10a. Época; 1a. Sala; SJF y su Gaceta; Libro IV, enero de 2012, Tomo 3; p. 2685.

79 Revisión en amparo directo. Resulta la vía adecuada para que la Suprema Corte de Justicia de la nación conozca de aquellas sentencias de los tribunales colegiados de circuito que no reparen una violación de derechos fundamentales cometida por un particular. [TA]; 9a. Época; 1a. Sala; SJF y su Gaceta; Tomo XXXIV, agosto de 2011; p. 230. 
y valores del ordenamiento jurídico, están reconociendo la dimensión objetiva de los derechos fundamentales pero, concretamente, la teoria de la eficacia horizontal mediata; en segundo lugar, al reconocer que los Tribunales Colegiados conocerán en amparo directo las posibles violaciones de derechos fundamentales que provengan de los tribunales ordinarios y que, en caso de violación por parte de los primeros, la SCJN conocerá en revisión de amparo directo, no está sino reconociendo la teoría de la asunción judicial.

La asunción judicial constituye, pues, una alternativa adecuada para remediar las violaciones de los derechos fundamentales cometidas por particulares. García torres y Jiménez blanco dicen que se trata de un: "hallazgo inapreciable porque concilia el velo de toda apariencia de Drittwirkung con el tácito acogimiento de la más vigorosa Drittwirkung latente", ${ }^{80}$ y Bilbao Ubillos la califica como una "ficción útil" ${ }^{11}$ y con "una importante función pedagógica". ${ }^{82}$

No obstante lo anterior, la asunción judicial no queda exenta de criticas y problemas de configuración. Se dice que es ilusoria en tanto que la conducta que se está recurriendo a través del amparo es la acción cometida por el Poder Judicial y no la del particular que transgredió el derecho, de tal forma que, tácitamente, se está aceptando que el único capaz de transgredir derechos fundamentales es el Estado. ${ }^{83}$

Pero el hecho de que el amparo no proceda como medio de solución para remediar las violaciones de derechos fundamentales en las relaciones privadas, y que por ello se tenga que acudir a la asunción judicial como alternativa de solución, no implica que se esté desconociendo la eficacia horizontal de los derechos. ${ }^{84}$ Más bien, con la asunción judicial se ha logrado proteger los derechos fundamental en las relaciones privadas.

Otro problema que plantea la teoría de la asunción judicial es que toda violación de derechos fundamentales en las relaciones privadas se reduce a una falta de protección del juez ordinario; lo que se controla es "la violación del deber de protección de los derechos fundamentales por parte de los órganos judiciales". ${ }^{85}$ Esto es cierto, pero eso no significa negar la existencia de la eficacia horizontal, más bien debe reconocerse el esfuerzo por tratar de proteger dichos derechos en

80 J. García Torres y A. JimÉnez-Blanco, Derechos fundamentales y relaciones entre particulares, op. cit., p. 140.

81 J. M. Bilbao Ubillos, La eficacia de los derechos fundamentales frente a particulares, op. cit., p. 223.

82 Idem, p. 228.

83 Así lo afirman GARCíA ToRRES y JimÉnEz BLANCo cuando dicen que: "curiosamente, ocurre que la doctrina de la Sentencia 78/1982 y de las que han seguido (a saber: no es objeto de amparo la violación producida por un acto de un particular, sino por un acto jurisdiccional), J. GARCíA TORRES y A. JiMÉNEZ Blanco, Derechos fundamentales y relaciones entre particulares, op. cit., p. 86.

84 Debemos adelantar, que no por el hecho de defender la eficacia inmediata de los derechos fundamentales en las relaciones particulares, creamos que el amparo deba proceder contra este tipo de violaciones. Se caería en el absurdo de que toda controversia sobre derechos fundamentales que surgiera en las relaciones particulares sería residenciable ante el Tribunal Constitucional a través del recurso de amparo.

85 M. MEdina, La vinculación negativa del legislador a los derechos fundamentales, McGraw-Hill, 1996, pp. 107-108. 
las relaciones particulares sin transgredir el sistema de garantías. Y aunque es la actuación del órgano judicial la que formalmente se enjuicia, ${ }^{86}$ en el fondo se analiza una actividad inter-privatos. Al resolver los casos de amparo el órgano judicial superior, ya sean los Tribunales Colegiados o la SCJN, está conociendo "la licitud constitucional de la conducta privada presuntamente lesiva de un derecho fundamental". 87

\section{CONCLUSIONES}

Los derechos fundamentales nacieron desde sus origenes más remotos como derechos de cada persona, que oponía como límites al poder del Estado; a esta concepción se le denominó dimensión subjetiva. Después de la Segunda Guerra Mundial, la concepción de los derechos fundamentales comprendió, junto a la dimensión subjetiva, la denominada dimensión objetiva. La dimensión objetiva de los derechos fundamentales implica concebirlos como principios y valores de todo ordenamiento jurídico, lo que significa a su vez que son el contenido axiológico sobre el que descansa todo Estado constitucional y democrático de derecho. La teoría de la dimensión objetiva de los derechos fundamentales ha tenido gran influencia en todos los países del mundo occidental, a tal grado que puede sostenerse que todo Estado que se jacte de ser democrático debe reconocer la dimensión objetiva de los derechos fundamentales.

En nuestro país, la dimensión objetiva de los derechos fundamentales no tiene un reconocimiento claro en el texto constitucional. El reconocimiento que se hace de la dignidad humana, concepto sobre el que descansa la dimensión objetiva, es tangencial. La declaración expresa de los derechos fundamentales como principios y valores del ordenamiento jurídico es inexistente. Pero esto no quiere decir que no exista dicha dimensión objetiva; si se hace un análisis a fondo de la Constitución, varios de sus artículos denotan el reconocimiento de los derechos fundamentales como principios y valores. Además, la Suprema Corte de Justicia de la Nación ha sido bastante clara en reconocer esta vertiente de los derechos y sus consecuencias.

De las consecuencias que derivan del entendimiento de los derechos fundamentales desde su dimensión objetiva solo los mandatos de acción al Estado se encuentran expresamente reconocidos en el artículo $1^{\circ}$ de nuestra Carta Magna. Falta ciertamente que, en la práctica, esos mandatos de acción vinculen de manera cierta y efectiva a todas nuestras autoridades, y falta también que se sancione la omisión de nuestras autoridades a los mandatos de acción que se desprenden de los derechos fundamentales.

También el efecto irradiación de los derechos fundamentales está siendo acogido por nuestros tribunales, y si bien resulta problemático aceptar que estos se proyectan ahora en todos los ámbitos del ordenamiento jurídico, los esfuerzos por parte de

86 J. M. Bilbao Ubillos, La eficacia de los derechos fundamentales frente a particulares, op. cit., p. 209.

87 Idem, p. 85. 
los jueces son plausibles. Más problemática resulta todavía la eficacia horizontal de los derechos y, aunque aquí se han encontrado más pronunciamientos, falta aclarar por parte de la Suprema Corte qué tipo eficacia será la que acogerá nuestra jurisprudencia constitucional, si una eficacia mediata o una eficacia inmediata; la cuestión tiene trascendencia sobre todo por la posible coartación que pudiese haber a la autonomía de la voluntad.

Por último, cabe destacar la solución que desde el ámbito procesal se está dando para proteger la violación de los derechos fundamentales en las relaciones particulares - la denominada en Europa asunción judicial, que sin llamarla de esa forma ya hemos acogido aquí-, y mientras no se abra plenamente el amparo contra las violaciones de los derechos fundamentales procedentes de particulares, parece ser la única forma de resolver o proteger de alguna manera estas transgresiones. En una frase, hemos de señalar que aunque no existe un reconocimiento expreso constitucional, la dimensión objetiva de los derechos fundamentales está presente en nuestro país, y que desde la doctrina y la jurisprudencia se están construyendo esfuerzos por un mejor y más claro entendimiento de esta teoría. Mientras más se reconozca, se entienda y se aplique la dimensión objetiva de los derechos fundamentales en nuestro país, más democráticos seremos.

\section{BIBLIOGRAFÍA}

AlEXY, R., Grundrechte als subjektive Rechte und als objektive Normen, en Recht, Vernunft, Diskurs, Frankfurt/M, Suhrkamp, 1995.

Balaguer Callejón, M. L., Interpretación de la Constitución y ordenamiento jurídico, Madrid, Tecnos, 1997.

BöCKENFÖRDE, E. W., Escritos sobre derechos fundamentales, Baden-Baden, Nomos Verlagsgesellschaft, 1993.

Canaris, C. W., "Grundrechte und Privatrecht", Archiv für die civilistische Praxis, 3, 1984, p. 207.

Cruz villalón, P., "Formación y evolución de los derechos fundamentales", Revista española de Derecho Constitucional, Año 925 (1989), p. 41.

García Torres, J., "Reflexiones sobre la eficacia vinculante de los derechos fundamentales", en Poder Judicial 19, 1988.

Hesse, K., Derecho constitucional y derecho privado, Madrid, Civitas, trad. de I. Gutiérrez, 1995.

Marías, J., "La teoría de los valores", en Historia de la Filosofia, Revista de Occidente 20 (1967), pp. 406-412.

Marshall Barberán, P., "Los derechos fundamentales como valores”, Revista Telemática de Filosofia del Derecho 10 (2006/2007), pp. 207-228.

Maunz, T. y G. DüRIG, Grundgesetz Kommentar, Band, V, Lfg. 20, marginal 29, p. 102. 
Medina, M., La vinculación negativa del legislador a los derechos fundamentales, McGraw-Hill, 1996.

Nipperderdey, H. C., Freie Entfaltung der Persönlichkeit, Die Grundrechte, IV, 2, Berlin, Dunker \& Humblot, 1962.

Pieroth, B. y B. Schlink, Grundrechte Staatsrecht II, Heidelberg, Müller Verlang, 1998, pp. 20 y ss.

Schneinder, H. P., "Peculiaridad y función de los derechos fundamentales en el Estado constitucional democrático”, en Revista de Estudios Politicos 7 (1979).

Silva Meza, J. N. y F. Silva García, Derechos fundamentales, México, Porrúa, 2013.

Smend, R., Constitución y derecho constitucional, Madrid, Centro de Estudios Políticos y Constitucionales, 1985.

STERN, K., "Das Staatsrecht der Bundesrepublik Deutschland. Bd. III/2", Allgemeine Lehren der Grundrechte, München, C. H. Beck, 1994, pp. 761-ss.

TRuTE, H. H., Die Forschung zwischen grundrechtlicher Freiheit und staatlicher Institutionalisierung, Tübingen, 1994.

Venegas Grau, M., Derechos fundamentales y derecho privado. Los derechos fundamentales en las relaciones entre particulares y el principio de autonomía privada, Madrid, Marcial Pons, 2004. 